\title{
EXPERIMENTAL INVESTIGATION OF DEFLECTOR'S ANGLE INFLUENCE ON ENERGY ABSORPTION
}

\author{
Roman Gieleta, Wiesław Barnat, Tadeusz Niezgoda \\ Military University of Technology \\ Department of Mechanics and Applied Computer Science \\ Gen. Sylwestra Kaliskiego Street 2, 00-908 Warszawa 49, Poland \\ tel.: +4822 6839226, +4822 6837201, +4822 6839849, fax: +48226839355 \\ e-mail: rgieleta@wat.edu.pl,wbarnat@wat.edu.pl,tniezgoda@wat.edu.pl
}

\begin{abstract}
Numerical simulations without preliminary validation and model verification are vulnerable to errors. Best results are obtained when full experimental research is provided. Such tests are expensive and may be dangerous. Due to cost control and personnel safety, studies are often done in scale. Scale can affect both construction dimensions and applied load. In this paper four different vehicle's bottoms are examined: flat bottom and 3 types of deflectors. The paper presents four different vehicle's bottom shapes in order to examine deflector angle influence on energy absorption.

The test included 4 cases: flat bottom broken-shaped deflector and deflectors with different apex angles $124^{\circ}$ and $144^{\circ}$. For all cases the distance between explosive and panel was approximately $400 \mathrm{~mm}$. The charge used was $100 \mathrm{~g}$ TNT. Flat bottom and deflectors were made of St 3 steel with $2 \mathrm{~mm}$ thickness. For the purpose of the research a special test stand to examine effects of detonation wave was used. The force measurement system was designed in Department of Mechanics and Applied Computer Science. As a result, force versus time plots were obtained. The use of any deflector decreases maximum force affecting vehicle's hull.
\end{abstract}

Keywords: IED, Improvised Explosive Device, hull resistance, deflector

\section{Introduction}

Contemporary warfare and peacekeeping missions conducted by Polish Army require equipment with adequate crew safety level. Troops are exposed to IED (Improvised Explosive Device) threats of unknown material and unlimited size. For that reason, sufficient safety level is required. The problem has been discussed in a few publications using numerical techniques [1-3]. On the other hand, there are also important publications about analytical and numerical solutions to above mentioned problems using experimental data $[4,5]$. Due to complicated nature of phenomenon and short time duration there is a constant need to validate numerical models. This paper describes experimental trials concerning mine resistance.

\section{Subject of research}

The paper presents four different vehicle's bottom shapes in order to examine deflector angle influence on energy absorption. The test included 4 cases: flat bottom (Fig. 1a), deflectors with different apex angles (Fig. 1b-d).

For all cases the distance between explosive and panel was approximately $400 \mathrm{~mm}$. The charge used was $100 \mathrm{~g}$ TNT. Flat bottom and deflectors were made of St3 steel with $2 \mathrm{~mm}$ thickness. Test stand used is shown in Fig. 2.

\section{Test equipment}

For the purpose of the research a special test stand to examine effects of detonation wave was used. The force measurement system was designed in Department of Mechanics and Applied Computer Science. Fig. 3 presents test equipment used during the experiment. 

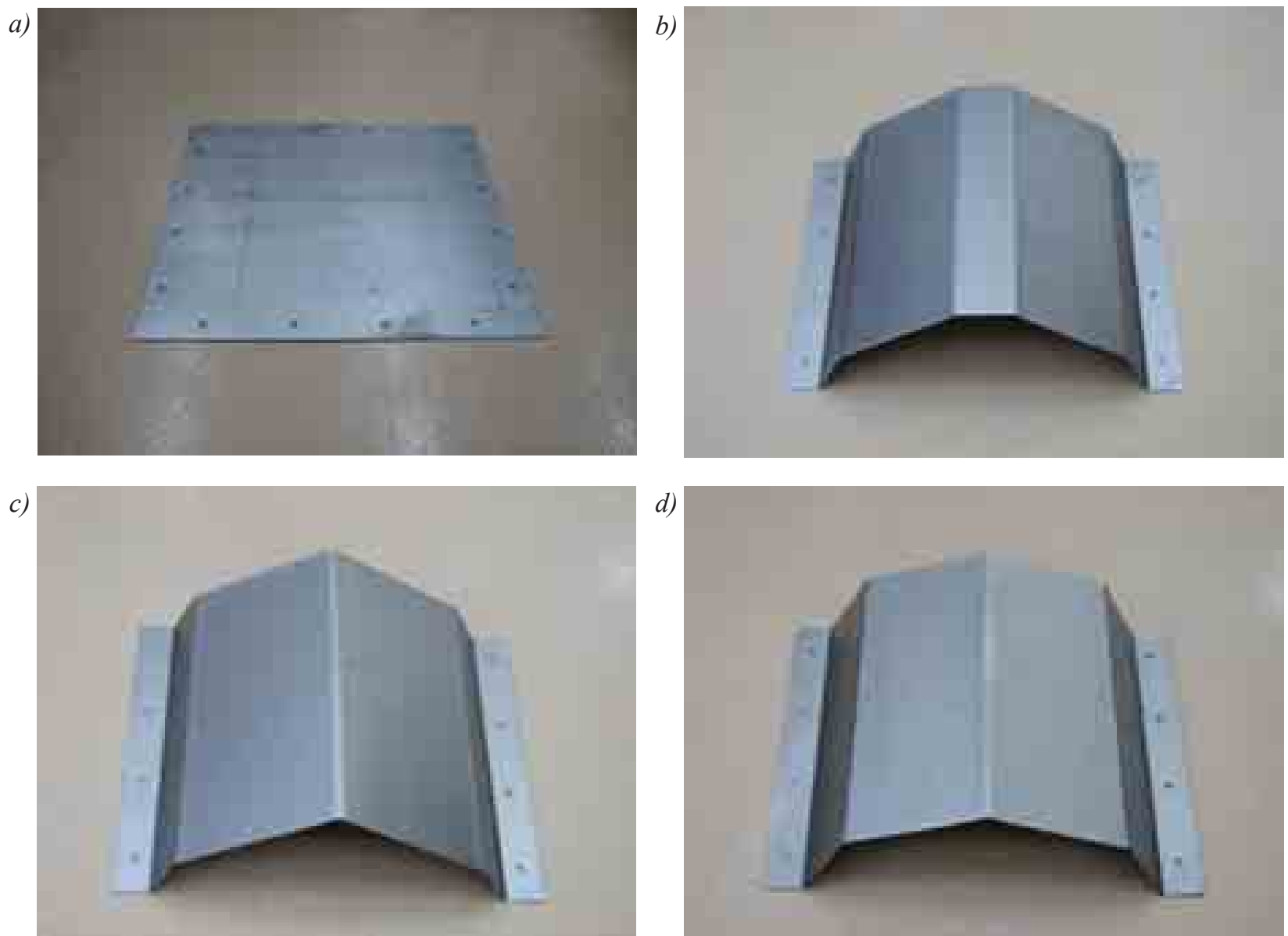

Fig. 1. Examined cases: flat bottom (a), broken-shaped deflector (b), deflector with apex angle $124^{\circ}$ (c), deflector with apex angle $144^{\circ}(d)$

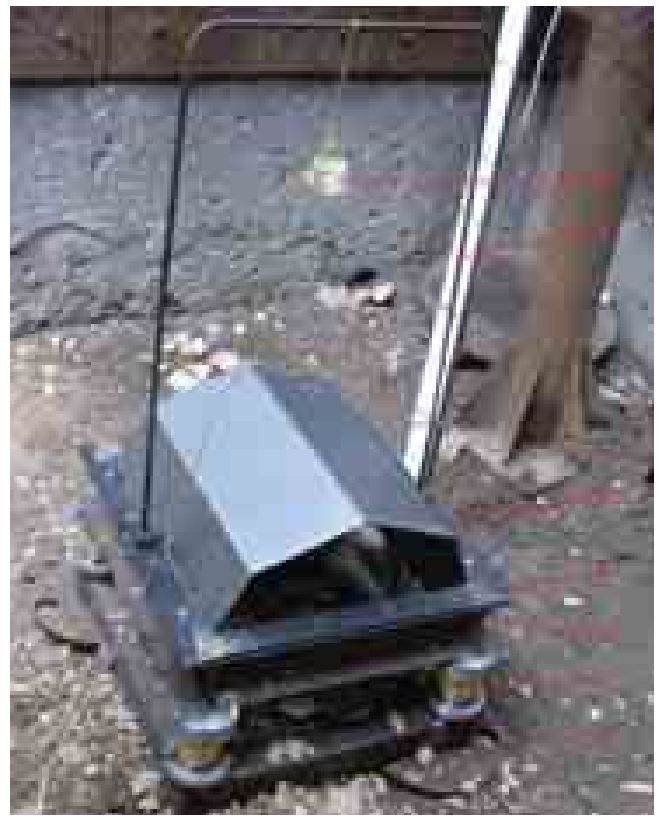

Fig. 2. Test stand used in experimental research: 1 - base, 2 - strain gauge force transducer (4 pieces), 3 - mounting frame, 4-upper mounting frame, 5-deflector, 6-explosive charge mount, 7 - explosive charge

The signals from the force transducer were amplified by DC amplifier's load cell $1001 \mathrm{MS}$ INFEL made by Swidnik. Registration runs were carried out using a National Instruments NI-USB measuring card model 6251 with a fast analog-to-digital (1.25 MHz sampling rate on one channel) 
and Toshiba Satellite laptop computer and a program to support measurement card. The apparatus used in the study is shown in Fig. 3.

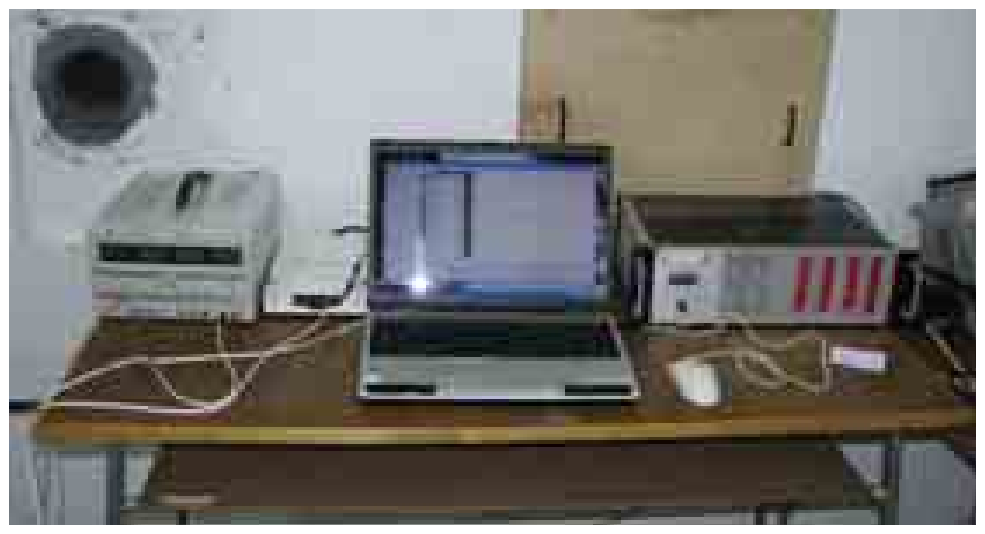

Fig. 3. Test equipment

\section{Test results}

After the experiment, obtained force plots were scaled in order to obtain force versus time plots. Fig. 4-7 show force versus time plots and final deformation states for each case (flat bottom or deflectors).

Test conducted on flat plate showed maximum force value of $2.2781 \mathrm{MN}$. For that case the value has the highest among all examined constructions.
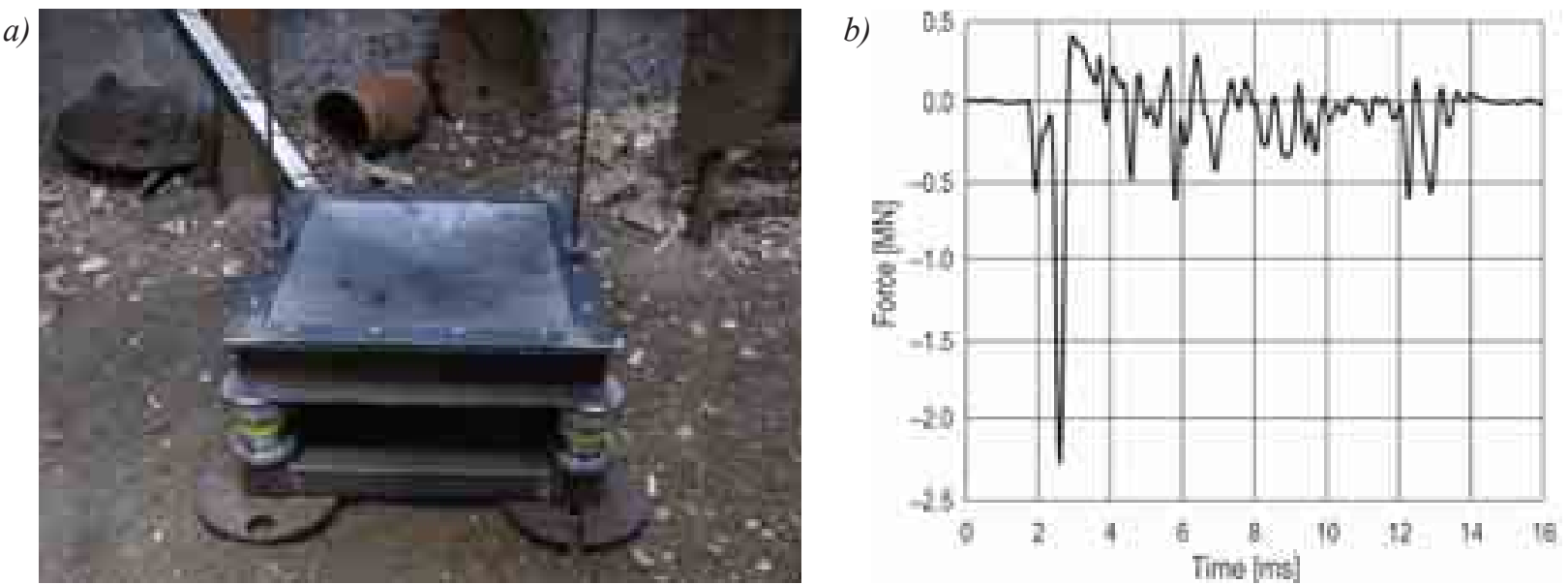

Fig. 4. Final deformation stage (a) and force vs. time plot (b) and for case I-flat bottom

Interesting fact is the deformation character of second case - broken-shaped deflector. As a result of pressure impact, plastic deformation occurred. The planes that were at angle to the detonation front were deformed only slightly. As a result, maximum registered force value was 4 times lower than in first case $-0.5463 \mathrm{MN}$.

For case III slight deformation of V-shape was observed. As a result o pressure impact (Fig. 6) the maximum registered force was twice lower than case I and twice higher than in case II $0.9615 \mathrm{MN}$.

Case IV, deflector with apex angle $144^{\circ}$, had as well only slightly deformed V-shaped walls. As a result of pressure impulse (Fig. 7) the registered force was twice lower than in Case I reaching $1.0686 \mathrm{MN}$.

Comparison of force values and plots are presented in Tab. 1. Fig. 8 shows force affecting structure versus deflector's apex angle. 

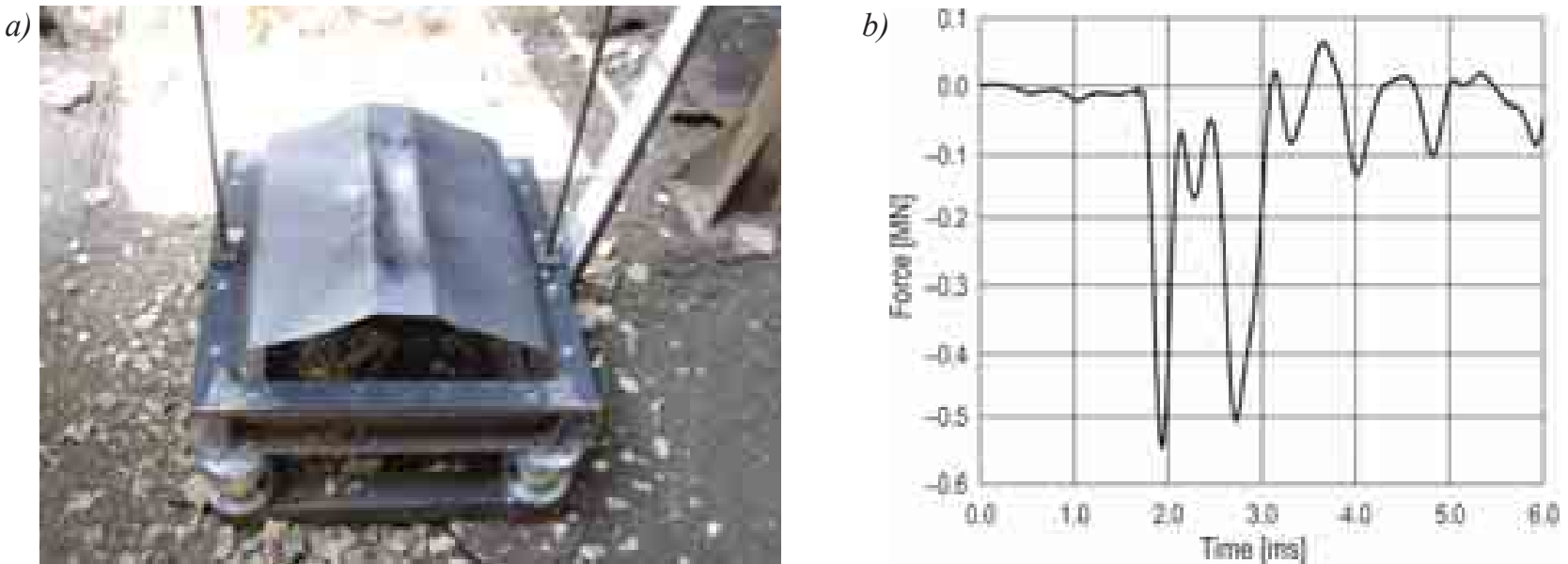

Fig. 5. Final deformation stage (a) and force vs. time plot (b) and for case II-broken-shaped deflector

a)

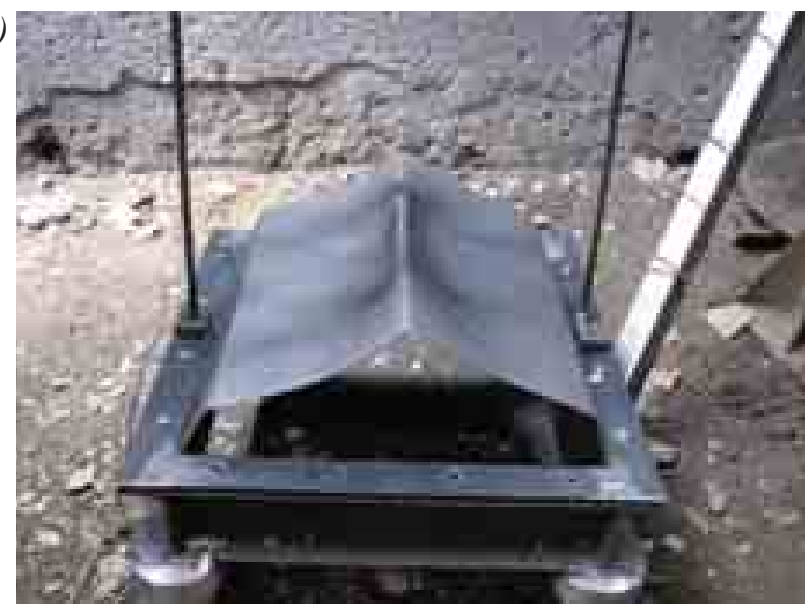

b)

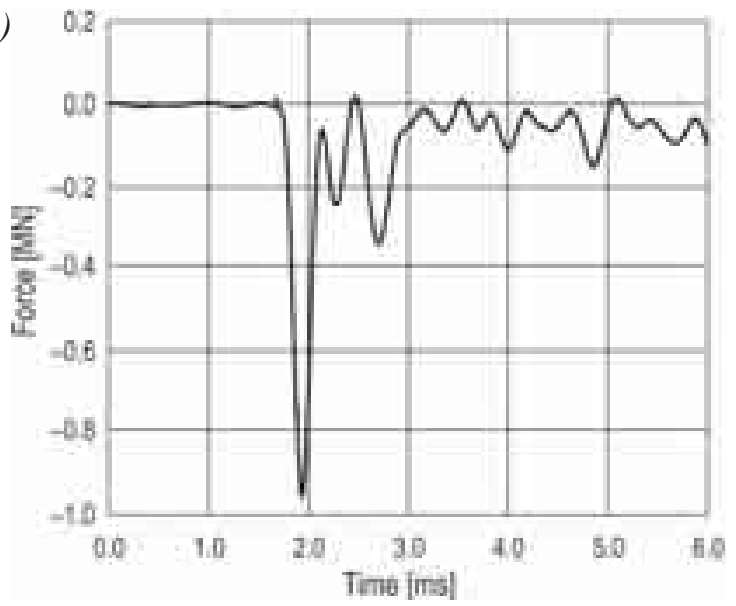

Fig. 6. Final deformation stage (a) and force vs. time plot (b) and for case III - deflector with apex angle $124^{\circ}$

a)

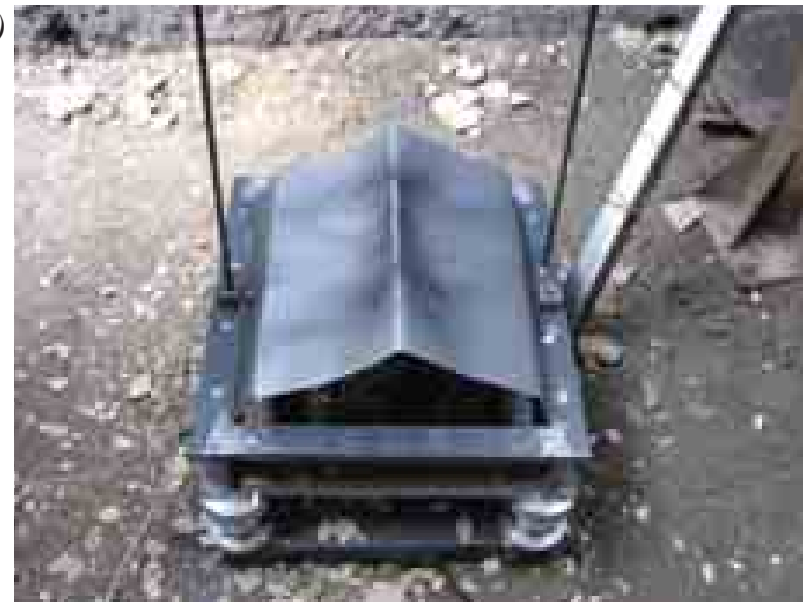

b)

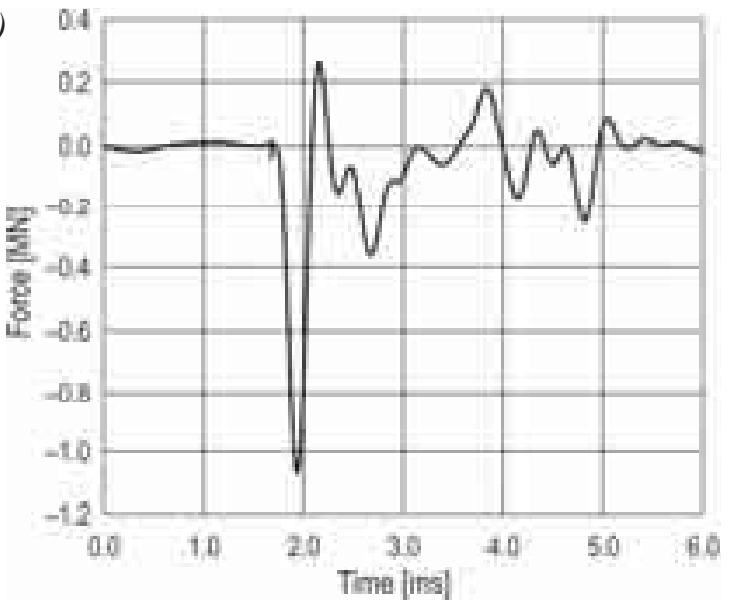

Fig. 7. Final deformation stage (a) and force vs. time plot (b) and for case IV-deflector with apex angle $144^{\circ}$

\section{Summary}

Presented results are a part of broader work on energy absorption problems. The use of any deflector decreases maximum force affecting vehicle's hull. What is more, studies showed that increase of apex angle increases the force. The correlation is not linear. Next step is to develop numerical models of deflectors and their optimization. 
Tab. 1. Results of the energy absorption properties for panels and deflectors

\begin{tabular}{|c|l|c|c|}
\hline Test No. & \multicolumn{1}{|c|}{ Sample } & Sample mass [kg] & Maximum force [MN] \\
\hline 1 & Steel plate $2 \mathrm{~mm}$ & 4.4 & 2.2781 \\
\hline 2 & Deflector I & 4.6 & 0.5463 \\
\hline 3 & Deflector II & 4.7 & 0.9615 \\
\hline 4 & Deflector III & 4.9 & 1.0686 \\
\hline
\end{tabular}

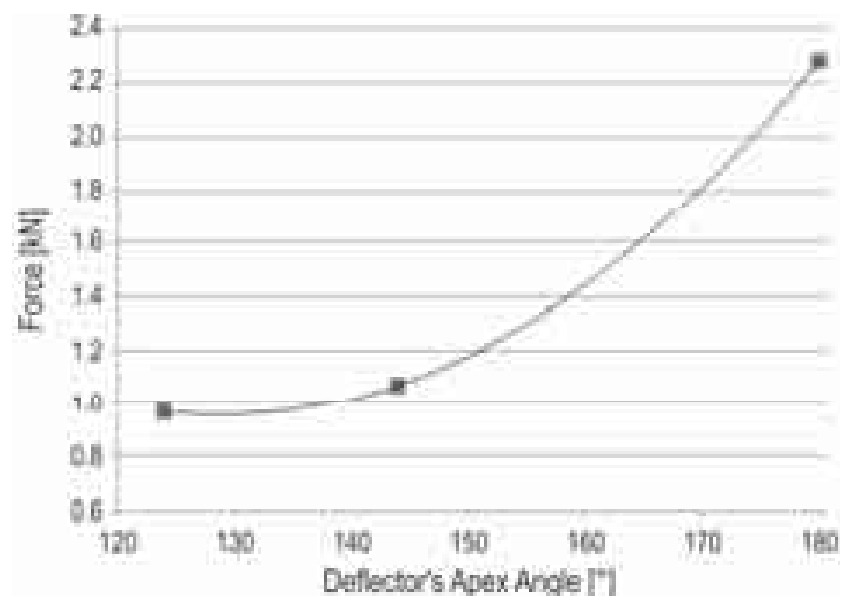

Fig. 8. Force affecting structure versus deflector's apex angle

\section{Acknowledgements}

The paper is a part of a development project No. O R00 0081 12, entitled: Group of modular wheeled armoured vehicles for reconnaissance and mine clearance of roads, supported by Ministry of Science and Higher Education, Poland. This support is gratefully acknowledged.

\section{References}

[1] Małachowski, J., Niezgoda, T., Research of Elastomeric Protective Layers Subjected to Blast Wave, Applied Mechanics and Materials, Vol. 82, pp. 680-685, 2011.

[2] Baranowski, P., Małachowski, J., Niezgoda, T., Numerical Analysis of Vehicle Suspension System Response Subjected to Blast Wave, Applied Mechanics and Materials, Vol. 82, pp. 728-733, 2011.

[3] Włodarczyk, E,. Podstawy fizyki wybuchu, Wydawnictwo WAT, 2012.

[4] Baker, W. E., Explosions in Air, University of Texas Press, Austin and London 1973.

[5] Staniukowicz, K. P., Fizyka wzrywa, Moskwa 1975. 